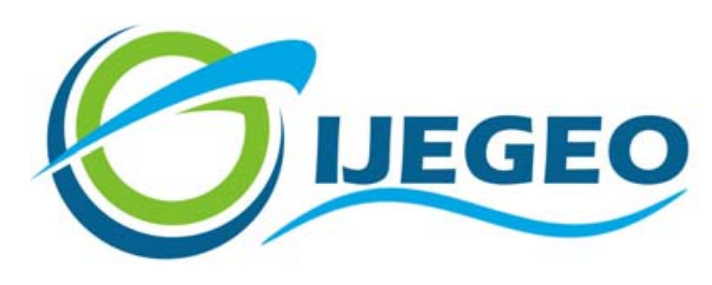

International Journal of Environment and Geoinformatics (IJEGEO) is an international, multidisciplinary, peer reviewed, open access journal.

\title{
Management of Carbon Footprint and Determination of GHG Emission Sources in Construction Sector
}

\section{Sena AHMETOĞLU, Ayşegül TANIK}

\author{
Chief in Editor \\ Prof. Dr. Cem Gazioğlu \\ Co-Editors \\ Prof. Dr. Dursun Zafer Şeker, Prof. Dr. Şinasi Kaya, \\ Prof. Dr. Ayşegül Tanık and Assist. Prof. Dr. Volkan Demir
}

Editorial Committee (August 2020)

\begin{abstract}
Assos. Prof. Dr. Abdullah Aksu (TR), Assit. Prof. Dr. Uğur Algancı (TR), Prof. Dr. Bedri Alpar (TR), Prof. Dr. Lale Balas (TR), Prof. Dr. Levent Bat (TR), Prof. Dr. Paul Bates (UK), İşad Bayırhan (TR), Prof. Dr. Bülent Bayram (TR), Prof. Dr. Luis M. Botana (ES), Assos. Prof. Dr. Gürcan Büyüksalih (TR), Prof. Dr. Nuray Çağlar (TR), Prof. Dr. Sukanta Dash (IN), Dr. Soofia T. Elias (UK), Prof. Dr. A. Evren Erginal (TR), Assoc. Prof. Dr. Cüneyt Erenoğlu (TR), Dr. Dieter Fritsch (DE), Prof. Dr. Çiğdem Göksel (TR), Prof.Dr. Lena Halounova (CZ), Prof. Dr. Manik Kalubarme (IN), Dr. Hakan Kaya (TR), Assist. Prof. Dr. Serkan Kükrer (TR), Assoc. Prof. Dr. Maged Marghany (MY), Prof. Dr. Michael Meadows (ZA), Prof. Dr. Nebiye Musaoğlu (TR), Prof. Dr. Masafumi Nakagawa (JP), Prof. Dr. Hasan Özdemir (TR), Prof. Dr. Chryssy Potsiou (GR), Prof. Dr. Erol Sarı (TR), Prof. Dr. Maria Paradiso (IT), Prof. Dr. Petros Patias (GR), Prof. Dr. Elif Sertel (TR), Prof. Dr. Nüket Sivri (TR), Prof. Dr. Füsun Balık Şanlı (TR), Prof. Dr. Uğur Şanlı (TR), Duygu Ülker (TR), Prof. Dr. Seyfettin Taş (TR), Assoc. Prof. Dr. Ömer Suat Taşkın (US), Dr. İnese Varna (LV), Dr. Petra Visser (NL), Prof. Dr. Selma Ünlü (TR), Assoc. Prof. Dr. İ. Noyan Yılmaz (AU), Prof. Dr. Murat Yakar (TR), Assit. Prof. Dr. Sibel Zeki (TR)
\end{abstract}

Abstracting and Indexing: TR DIZIN, DOAJ, Index Copernicus, OAJI, Scientific Indexing Services, International Scientific Indexing, Journal Factor, Google Scholar, Ulrich's Periodicals Directory, WorldCat, DRJI, ResearchBib, SOBIAD 


\title{
Management of Carbon Footprint and Determination of GHG Emission Sources in Construction Sector
}

\author{
Sena Ahmetoğlu, iD Ayşegül Tanık* iD \\ ITU, Faculty of Civil Engineering, Environmental Engineering Department, Istanbul, TR \\ * Corresponding author: A. Tanık \\ *E-mail: tanika@itu.edu.tr
}

Received 25 April 2019

Accepted 11 May 2020

How to cite: Ahmetoğlu and Tanık (2020). Management of Carbon Footprint and Determination of GHG Emission Sources in Construction Sector, International Journal of Environment and Geoinformatics (IJEGEO), 7(2): 191-204. DOI: 10.30897/ijegeo.726913

\begin{abstract}
Carbon footprint involves the calculation of direct and/or indirect emissions of fossil fuels that emit greenhouse gases (GHG) which in turn lead to greenhouse effect responsible of global warming. The resulting carbon dioxide $\left(\mathrm{CO}_{2}\right)$ due to the activities of the individuals/institutions emerges into the atmosphere with the consumption of energy. The amounts of emissions throughout the world in general and in Turkey, and the main reasons of these emissions are explained in this study. Carbon footprint management and tracking since 1990's in Turkey are underlined, and carbon tax and carbon trade terminologies are introduced. Scope classification for determining emissions according to three classification of ISO 14064 Greenhouse Gas Calculation and Validation Management System is described. Scope-1 covers the activities that create direct carbon footprint. In this context, the fossil fuels used by the projects for heating or energy needs, and the emissions from the fuels of the vehicles are taken into consideration. Within Scope-2, the carbon footprints of the emissions caused by the electrical energy consumed through the projects are considered. Scope-3 is an indirect carbon footprint and includes emissions from projects that are not directly emission-driven projects. With this study, it is aimed to address the carbon footprint caused by the entire construction sector that extends from the production of construction materials to the construction and post-construction (operation) stages. This sector is focused on due to its significance regarding GHG emissions globally. Emissions from non-owned or uncontrolled sources such as production, transportation, leased assets, outsourced services and disposal of the wastes generated during the construction and/or operation stages of different building typologies should be included in the carbon footprint calculations.
\end{abstract}

Keywords: Carbon Footprint, Construction Sector, Climate Change, GHG Emissions, Turkey.

\section{Introduction}

Carbon footprint and greenhouse gas (GHG) emission calculations have gained importance and have become one of the most emphasized topics in the world especially in the recent years in order to resolve the problems caused by the disruption of the natural balance due to the unconscious consumption of natural resources by the humans. Carbon footprint is the environmental damage of the activities, measured in units of carbon dioxide $\left(\mathrm{CO}_{2}\right)$, depending on the amount of GHG produced. This measure is classified and evaluated as a primary (direct) or secondary (indirect) carbon footprint. $\mathrm{CO}_{2}$ emissions directly arising from the burning of fossil fuels, domestic energy consumption and transportation (such as vehicles and aircraft) are referred as primary carbon footprint; whereas, secondary carbon footprint are indirect $\mathrm{CO}_{2}$ emissions extending from the manufacture of the products that humans use till their deterioration from the entire life cycle (Özsoy, 2015; Bayırhan, et al., 2019; Talapatra, 2019). Thus, the secondary carbon footprint is more comprehensive and includes the primary carbon footprint emissions.

Intergovernmental Panel on Climate change (IPCC) founded in 1988 by the World Meteorological Organization (WMO) and the United Nations
Environment Program (UNEP) conducts scientific studies on climate change that human beings are exposed to and that has an increasingly felt impact on life. It publishes reports containing evaluations about the impacts of climate change. In the $5^{\text {th }}$ evaluation report published in 4 parts in 2013 and 2014, the below referred findings had been stated;

- The warming in the climate system continues and the changes observed since 1950 have not been seen in the previous decades and millennia, the atmosphere and the oceans have been heated by $0.85{ }^{\circ} \mathrm{C}$, the snow and ice melted, the sea level increased, and the concentration of GHG increased,

- Last 30 years have been the hottest decades (1983-2012) since 1850,

- The warming of the oceans increased the energy stored in the climate system, $90 \%$ of the calculated energy accumulated between 19712010,

- Over the past 20 years, volume losses continue to occur in Greenland and Arctic icebergs and spring snow cover has decreased in the Northern Hemisphere, 
- The rate of sea level rise that has been occurring since the $19^{\text {th }}$ century is more than the rise in the last 2000 years, and the global sea level between 1901-2010 increased by $19 \mathrm{~cm}$,

- $\mathrm{CO}_{2}$ increased by $40 \%$ compared to the preindustrial revolution, oceans absorbed $30 \%$ of human emitted $\mathrm{CO}_{2}$ which caused the seas to acidify,

- Since the $4^{\text {th }}$ evaluation report published in 2007 and according to RCP6.0 and RCP8.5 scenarios, climate models have been developing and, all the models and scenarios expected the temperature to increase by more than $1.5^{\circ} \mathrm{C}$ towards the end of the $21^{\text {st }}$ century (except RCP2.6).

- Extraordinary events like hot air waves, floods and droughts, sea level change, tropical and extremely tropical conditions have increased and will continue in the second half of the $20^{\text {th }}$ century,

- Climate change will affect shelter security as well as food security,

- It is also emphasized that there are possibilities and practices (renewable energy, energy efficiency, stopping deforestation, carbon capture, etc.) to make the world livable for future generations (Edenhofer et al., 2014; Sunturlu, 2017; Ülker et al., 2018).

The control and reduction of carbon footprint, which includes the supply and transportation processes of the raw material consumed in the production stages of every vehicle and equipment used in human activities, and directly affected by the amount of fossil fuel consumed, is one of the most important elements of the combat against global warming and climate change.

In a survey carried out in 2007 on the ecological footprint components of Turkey like carbon footprint, agricultural footprint, forest footprint, pasture footprint, built footprint and fisheries footprints, carbon footprint demonstrated the largest share of the ecological footprint with $46 \%$ (WWF-Turkey, 2012). Turkey, being one of the countries that made commitments with the Paris Peace Treaty, agreed to reduce the consumption of fossil fuels in meeting the increasingly emerging energy needs associated with increasing industrialization, promote the use of renewable energy and, avoid the unconscious use of natural resources. In addition, measures need to be taken regarding GHG, which in turn lead to greenhouse effect that consequently affects climate change and global warming.

\section{Carbon Footprint in the World}

Carbon footprint is a tool that provides monitoring and measurement of GHG emissions and control of different scale reduction practices. It is caused by $\mathrm{GHG}$, the effects of which were manifested by the spread of industrialization in the 1930s, was measured from 9411 $\mathrm{MtCO}_{2}$ in 1960 to $36573 \mathrm{MtCO}_{2}$ in 2018 (Url-1). In Figure 1, the change of countries' carbon footprint in $\mathrm{MtCO}_{2}$ from 1960 to 2018 is marked on the world map. The information is provided from the global carbon atlas. The figure shows the total amount of direct and indirect GHG emissions from country's operations.

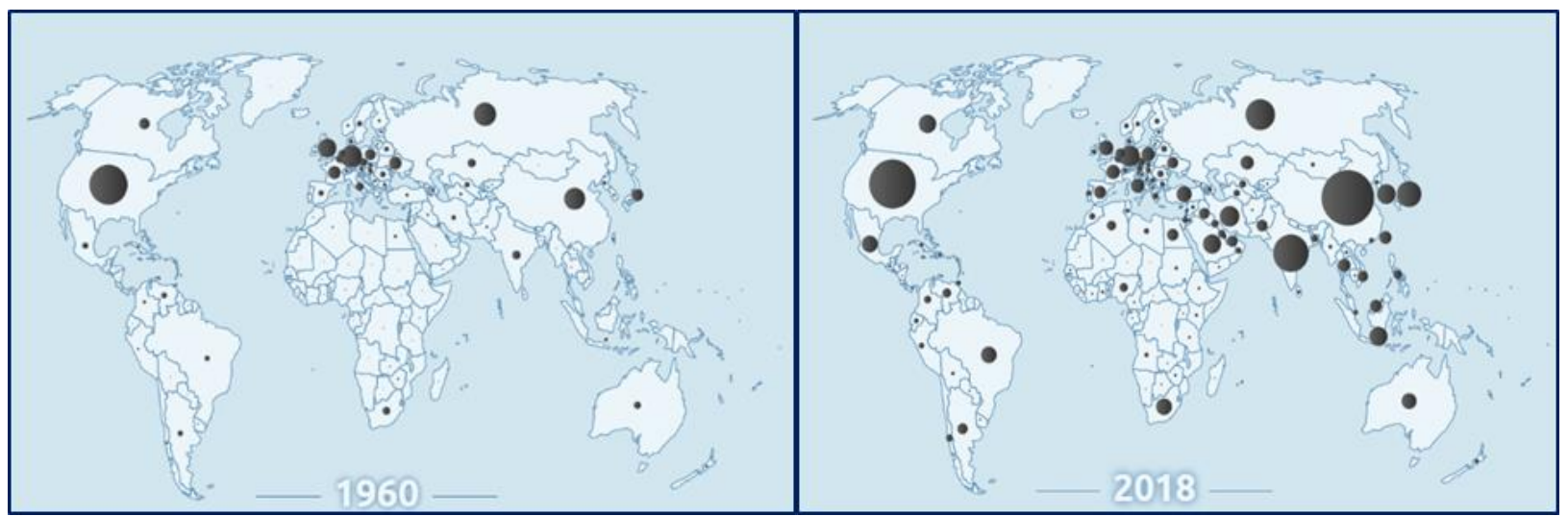

Fig. 1. Carbon footprint change of countries in 1960 and in 2018 (Url-1).

\section{Climate change performance index}

While the five countries with the highest total GHG emissions in 1960 were USA, Russian Federation, Germany, China and UK respectively, the top five countries in 2018 were China, USA, India, Russian Federation and Japan, respectively. While the total amount of emissions of five countries that caused the highest GHG emissions in 1960 was calculated to be $5955 \mathrm{MtCO}_{2}$; this amount reached to $21008 \mathrm{MtCO}_{2}$ in 2018 (Url-1). It can be stated that the percent increase of the total GHG emissions recorded in the world between 1960 and 2018 is in line with that of the top five countries.
Germanwatch, the German Civil Society Organization (NGO), evaluates and ranks the countries' climate change performances in order to increase transparency in international climate policies. The methodology of the index scale is primarily based on objective indicators. $80 \%$ of the entire evaluation depends on emission indicators $(30 \%$ for emission levels, $30 \%$ for emission development), efficiency indicators (efficiency level $5 \%$ and recent development trend $5 \%$ ) and on renewable energy indicators (8\% development and $2 \%$ share of total basic energy supply) (Fırat et al., 2017; Gazioğlu, 2018). Considering that none of the 60 countries analyzed showed the effort to take the first three places 
in climate change, the first three places were left empty. According to the 2019 report, Turkey is ranked as $50^{\text {th }}$ country with 40.22 points. The three countries with the highest scores were Sweden with 76.28 points, Morocco with 70.48 points and Lithuania with 70.47 points. Saudi Arabia ranked as the last $\left(60^{\text {th }}\right)$ country with 8.82 points (Url-2).

\section{Carbon Footprint in Turkey}

Carbon footprint includes emissions from fossil fuels consumed, the carbon produced during the production of imported products, the share of emissions caused by the country's international trade, and carbon emissions other than fossil fuels (WWF-Turkey, 2012). Turkey, acting as one of the parties negotiated on a national platform, has started to keep track of GHG emissions. Turkish Statistical Institute (TSI) has published the data on GHG emissions of the country with respect to different years as shown in Table 1. According to the given values, the total GHG emissions in Turkey are increasing. It can be stated that the studies and applications put forward so far are insufficient to create the desired effect, and more serious and feasible actions are needed.

Table 1. Turkey's GHG emissions during 2000 - $2018\left(\mathrm{MtCO}_{2}\right)(\mathrm{Url}-3)$.

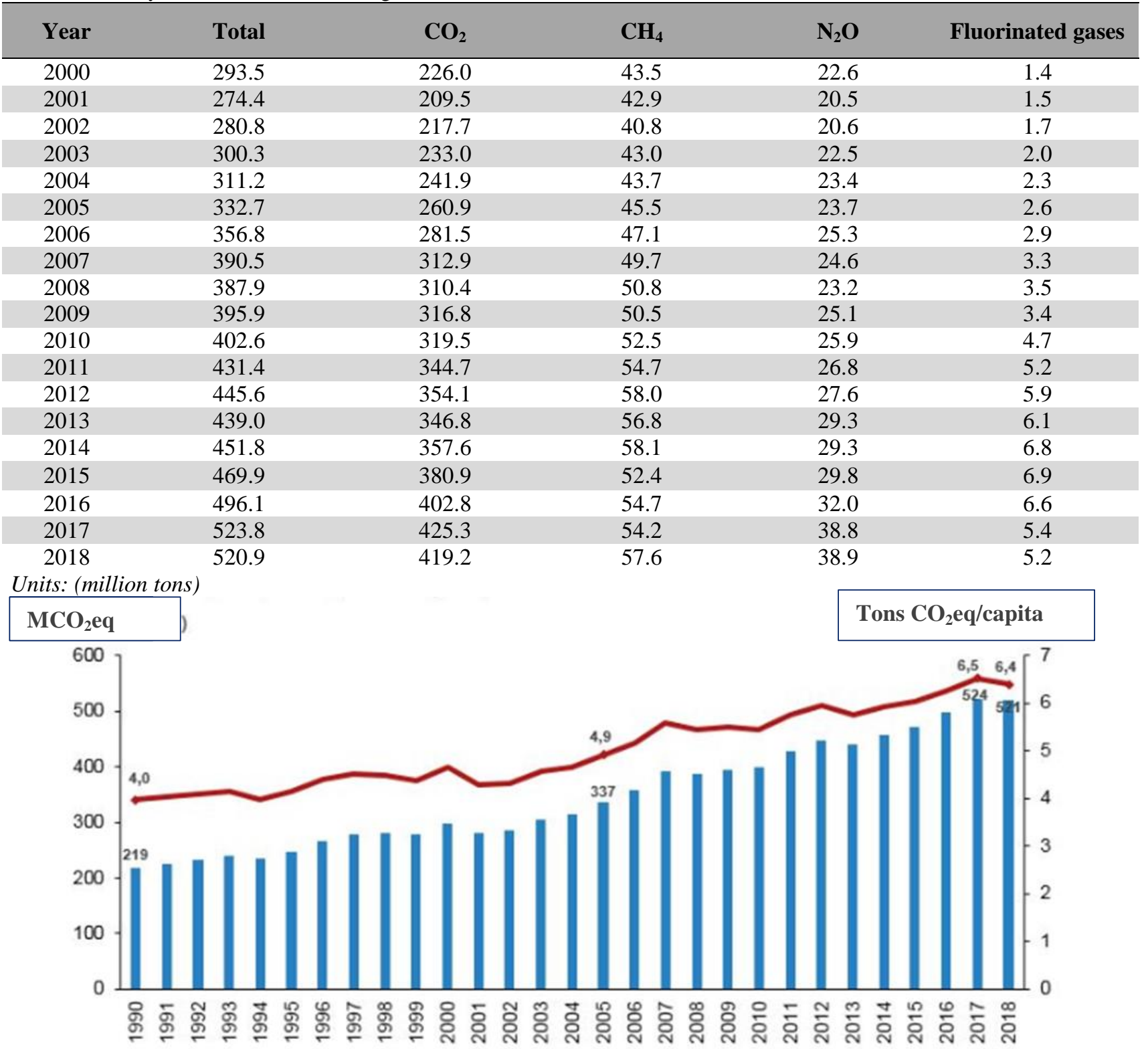

Fig. 2. GHG emissions per capita in Turkey (Url-3).

With the increase in industrial activities and fossil fuel consumption, the rise in population density also has an impact on GHG emissions, expressed in Table 2; show an ever-increasing upturn. The values published by TSI and given in Figure 2 for the years 1990-2018 indicate that although the population increase, the rise in GHG emissions is higher; and therefore, the amount of emission per capita exerts an increasing trend. As the $\mathrm{CO}_{2}$ equivalent, the total GHG emission in 2018 almost doubled up compared to 2000. While $\mathrm{CO}_{2}$ equivalent emission per capita was calculated as 3.8 tons in 1990 , this value was calculated as 4.9 tons in 2005 and 6.4 tons in 2018, respectively (Url-3). Depending on the total GHG emissions and activities per capita along with the 
gradual increase in the level of intensity, a distinction can be made among the major emission sources between 2000 and 2018. Table 2 represents major GHG emission sources by sectors in Turkey during the inspected years. While the sectoral resource that caused the biggest GHG emission in 2000 was energy with $212.3 \mathrm{Mt} \mathrm{CO}_{2} \mathrm{e}$, energy had the biggest share in 2018 with $373.1 \mathrm{Mt}$ $\mathrm{CO}_{2} \mathrm{e}$.

\section{Carbon Footprint Management and Tracking}

The most accepted principle in GHG emission management on a country basis and globally is the 'measured can be controlled' approach. In this approach, the first and most important step related to carbon management is the inventory study where the current emissions are determined accurately, completely and transparently, covering all sectors and institutions. Efforts to reduce the amount of emissions and measures to be taken can possibly provide healthy results with the inventory study of the current situation based on realistic and reliable measurements and calculations. A strategy and action plan that determines the content, timing and prioritization of the measures to be taken after determination by inventory work should be created.

Table 2. GHG emission amounts $\left(\mathrm{MtCO}_{2} \mathrm{e}\right)$ by sectors (Url-4).

\begin{tabular}{ccccccc}
\hline Year & Total & $\begin{array}{c}\text { Change compared to } \\
\mathbf{2 0 0 0}(\boldsymbol{\%})\end{array}$ & Energy & $\begin{array}{c}\text { Industrial processes } \\
\text { and product use }\end{array}$ & Agriculture & Waste \\
\hline 2000 & 293.5 & - & 212.3 & 26.6 & 40.0 & 14.5 \\
2001 & 274.4 & -0.6 & 195.2 & 26.6 & 37.7 & 15.0 \\
2002 & 280.8 & -4.3 & 201.9 & 27.9 & 35.5 & 15.4 \\
2003 & 300.3 & 2.2 & 216.4 & 29.1 & 38.9 & 15.9 \\
2004 & 311.2 & 6.0 & 223.1 & 31.8 & 39.8 & 16.5 \\
2005 & 332.7 & 57.9 & 240.3 & 34.6 & 40.8 & 16.9 \\
\hline 2006 & 356.8 & 13.3 & 260.0 & 37.4 & 42.0 & 17.5 \\
\hline 2007 & 390.5 & 33.0 & 291.0 & 40.0 & 41.7 & 17.7 \\
2008 & 387.9 & 32.2 & 288.4 & 41.9 & 39.7 & 17.8 \\
2009 & 395.9 & 34.9 & 294.0 & 43.4 & 40.6 & 17.9 \\
\hline 2010 & 402.6 & 37.2 & 292.3 & 49.2 & 42.8 & 18.2 \\
2011 & 431.4 & 47.0 & 313.4 & 54.4 & 45.1 & 18.5 \\
\hline 2012 & 445.6 & 51.8 & 320.1 & 56.8 & 50.6 & 18.1 \\
\hline 2013 & 439.0 & 49.6 & 308.8 & 59.8 & 53.6 & 16.8 \\
\hline 2014 & 451.8 & 53.9 & 321.3 & 60.2 & 53.7 & 16.6 \\
2015 & 469.9 & 60.1 & 339.7 & 59.6 & 53.7 & 17.0 \\
\hline 2016 & 496.1 & 69.0 & 361.0 & 62.4 & 56.5 & 16.2 \\
\hline 2017 & 523.8 & 78.5 & 379.9 & 63.6 & 62.8 & 17.4 \\
\hline 2018 & 520.9 & 77.5 & 373.1 & 65.2 & 64.9 & 17.8 \\
\hline
\end{tabular}

Units: (million tons)

Table 3. Methods and standards for the calculation and evaluation of GHG emissions

\begin{tabular}{ll}
\hline Approach & Method/Standard \\
\hline Greenhouse Gas Reduction Calculations & IPCC Calculations \\
Inventory Studies for Institutions and Organizations & ISO 14064 \\
& $\begin{array}{l}\text { GHG Protocol } \\
\text { Carbon Trade }\end{array}$ \\
Life Cycle Assessments & ISO 14048. PAS 2050. PAS 2060 \\
Carbon Trade and Carbon Tax & Mandatory Carbon Markets \\
& Voluntary Carbon Markets (VCS, Gold Standard etc.)
\end{tabular}

GHG inventory targets the determination of all direct and indirect GHG emitted from emission sources. Emission of different $\mathrm{GHG}$ is calculated as $\mathrm{CO}_{2}$ equivalent by using Global Warming Potential (GWP) in the GHG inventory. This inventory is created by taking into account three main elements in accordance with a determined standard method. These are;

- Determination of inventory limits,

- Measuring or calculating GHG, and

- $\quad$ Reporting of GHG.

The most common standards used in inventory studies are the ISO 14064 Greenhouse Gas Calculation and
Verification Management System established by the International Standards Organization, and the Greenhouse Gas Protocol prepared by the World Business Council for Sustainable Development Business Council (WBCSD) and the World Resources Institute (WRI). ISO 14064 is an internationally recognized standard that includes the steps and details of GHG inventory calculation and validation. GHG Protocol is a guide that contains information on how to calculate and report, as well as referring to requirements. The reports, methods and standards regarding the calculation and evaluation of GHG emissions are specified in Table 3. The methods and standards for the calculation and 
evaluation of GHG emissions are adapted from Toröz (2015).

These standards enable calculations of direct GHG emissions and other indirect emissions from the energy generated in the production of electricity, heat or steam consumed in the activities performed. The verification and certification of the emission inventory created for an organization by an independent audit firm enables its validity in the carbon market and the availability of excess carbon in the carbon trade.

\section{ISO 14064 Greenhouse Gas Calculations and Verification Management System}

ISO 14064 is a series of proposed standards, issued by ISO in 2006, used as a guide for the consistent reporting of GHG emissions and removals of an organization, for GHG emission reduction, or for improvement projects, for verification and validation of GHG notifications. ISO 14064-1 contains detailed information on the principles and conditions for the design, development, management and reporting of GHG inventories at enterprise or company level. This standard covers the requirements for the determination of GHG emission limits, the calculation of an organization's GHG emissions and removals, and the identification of its specific measures or activities to improve GHG management. In addition, in this standard, there are conditions and guidelines regarding inventory quality management, reporting, internal audit and the responsibilities of the organization for verification activities (ISO 14064-1, 2007). Within the scope of ISO 14064-1, details of three scopes are determined for GHG inventory study and reporting. The scope is an indication of which items will be included in the GHG emission calculations and measurements. Thus, the intensity of the activities and consumption of the organization should be taken into consideration. The scope definitions (Figure 3) that directly affect the validity of the inventory study are as follows:

- Scope 1: GHG emission released from GHG sources owned or controlled by an organization.

- Scope 2: It is the GHG emission that occurs during the production of electricity, heat or steam that is supplied and consumed by an organization.

- Scope 3. Apart from energy, it is the GHG emission arising from the resources owned or controlled by other organizations resulting from an organization's activities.

ISO 14064-2 focuses on specially designed GHG projects or project-based activities to reduce GHG emissions. This standard contains the principles and conditions for identifying the main scenarios of the project and monitoring, evaluating and reporting the performance of the project according to these basic scenarios. It is a guide for GHG projects to be validated and verified. ISO 14064-3 on the other hand, provides detailed information on principles and requirements for validating GHG inventories and projects (Wintergreen and Delaney, 2007).

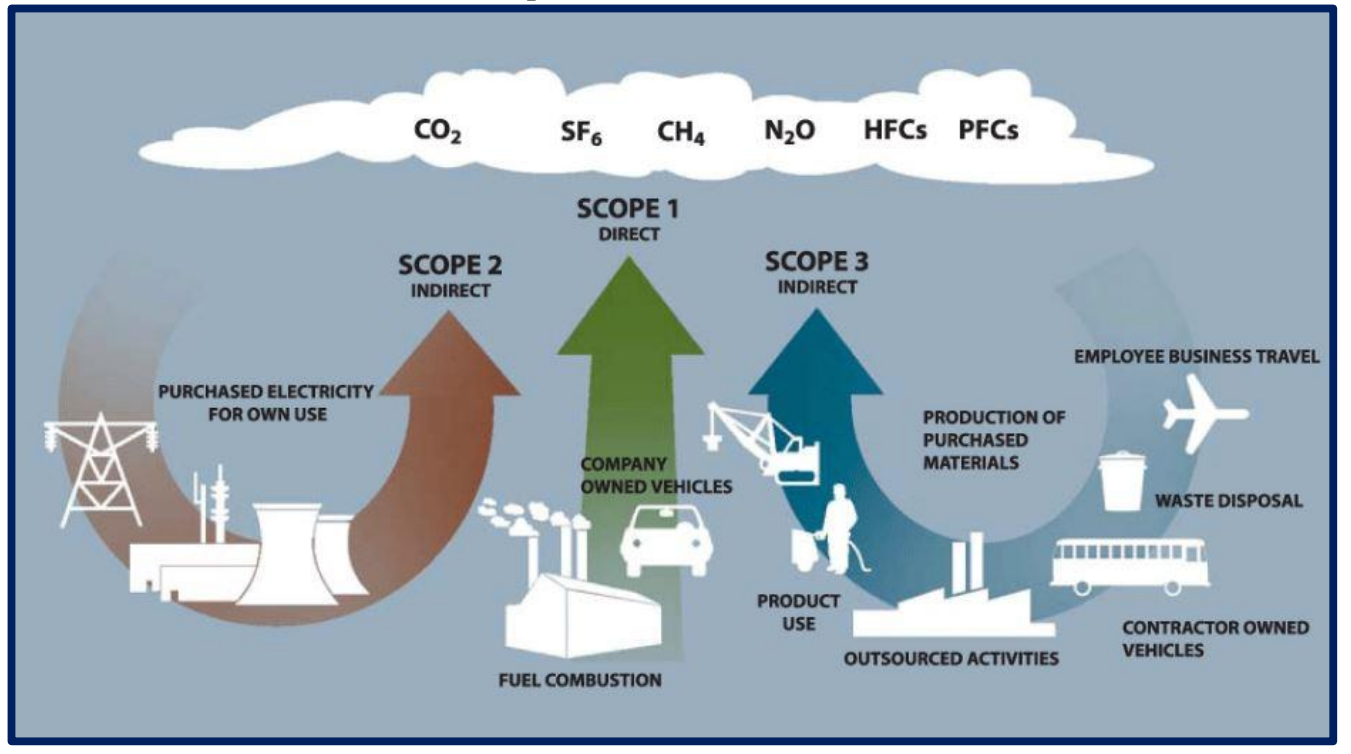

Fig. 3. GHG resources under ISO 14064 (WRI/WBCSD, 2004).

\section{Verification of National Regulations and Reports on Tracking GHG Emissions}

The need for a trans-national effort on global warming and climate change is demonstrated with the Kyoto Protocol. With the Paris Agreement adopted by the approval of 195 countries at the UN Conference on the Framework Convention for Climate Change (UNFCCC) in December 2015, the historical processes in which the practices required to take global responsibility in combating climate change are turned into sanctions. As such, a more stable, balanced and healthy planet in the context of sustainability is perceived as an important step for fairer societies and stronger economies. In Turkey, GHG emissions from sectors such as electricity and steam production, cement, iron-steel, refinery, ceramics, lime, paper and glass manufacturing have the largest share in total GHG emissions. Therefore, the Regulation on the Tracking of GHG Emissions has been initially published in the Official Gazette dated April 25, 2012 and numbered 28274.

The Regulation on the Tracking of GHG Emissions by making changes/updates on issues such as the effective 
dates was re-published in the Official Gazette dated May 17, 2014 and numbered 29003 to meet certain sectoral and institutional needs and requirements listed below;

- Verification of monitoring plans,

- Authorization of the verifying institutions,

- Elements of the contract for verification,

- Verification fee and accreditation obligation.
Thus, the 2012 Regulation was repealed. The legislation states that the facilities included in Annex-1 of the Regulation that carry out the activities causing excessive emission will be subject to regular monitoring, reporting and verification processes every year. Within the scope of the Communiqué, it is required to prepare Monitoring Plans by direct measurement or calculation method, and to submit them to the Ministry of Environment and Urbanization through the Environmental Information System. The follow-up cycle of GHG emissions specified in the Regulation is given in Figure 4.

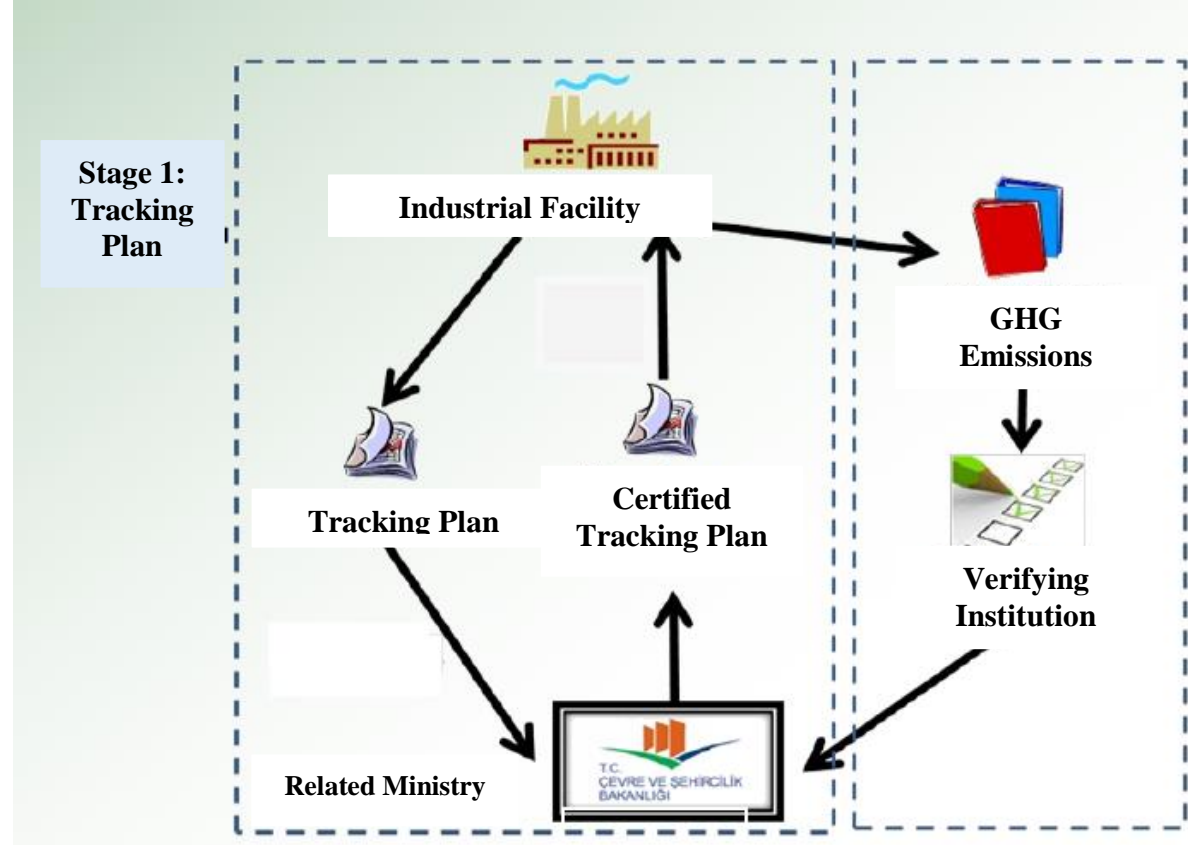

Stage 2:

Annual

Reporting

Fig. 4. GHG emission tracking and reporting cycle (Url-5).

With the recent amendments made in the regulation, revised version entered into force as the "Regulation on the Amendment of the Regulation on the Tracking of GHG Emissions" in the Official Gazette dated 31.05.2017 and numbered 30082 .

While creating the Monitoring Plan, $\mathrm{CO}_{2}, \mathrm{CH}_{4}, \mathrm{~N}_{2} \mathrm{O}$, HFCs, PFCs and SF6 gases should be taken into consideration and the scope of the plan should be determined accordingly. Items to be determined step- bystep while preparing the Monitoring Plan are as follows;

- Facility boundaries,

- Facility category, account/measurement approach, step requirements,

- Data sources list (activity data and calculation factors),

- Laboratories to be used, standards, sampling plan,

- $\quad$ Risk analysis and control activities (Url-5).

Organization and/or company activities should be prioritized in choosing the monitoring method.

\section{Detection of emissions by direct measurement}

Direct measurement method includes $\mathrm{CO}_{2}$ concentration and flow of transferred gases that are measured, and $\mathrm{CO}_{2}$ transfer monitored between facilities. It is the determination of the emission amount as a result of continuous measurement of the relevant GHG concentration in the flue gas and the flue gas flow by means of measuring instruments placed at the reference points.

\section{Detection of emissions by calculation method}

Calculation method is used to determine the emission amount of the facility by multiplying the activity data used in line with the activities performed by the emission factors (EF) published by the relevant institutions. The Regulation on the Tracking of GHG Emissions includes the $\mathrm{EF}$ and the equation related to the oxidation factor (OF) (equation 1).

\section{Amount of Emission $=$ Activitiy Data $x E F \times O F$}

(Eq. 1)

Emission factors determined by IPCC can be used in calculations if accepted by the Ministry.

\section{Carbon tax}

Climate change is considered as the biggest global environmental problem today and is seen as a profound danger on the living opportunities and ecological balance of the next generations. Extraordinary weather-related events such as excessive precipitation, hurricanes, floods that have increased between 1990 and 2000 still maintain 
their effects, and resulting causes are represented by great economic losses.

The losses that led the governments to tax the amount of emissions and compensate for economic losses in this way. Accordingly, carbon tax, which primarily aims to reduce carbon emissions and the use of natural resources, has emerged. The first emission tax application was used in Finland in 1990. Later, the carbon tax introduced by Norway in 1991 resulted in a decrease of carbon emissions arising from the power plants in the country by $21 \%$ (Kulu, 2001; Alıc1 and Yildiz, 2012). Since the emission amount is difficult to measure directly in practice, carbon taxes are classified under three main categories (Vural, 2012):

- Carbon tax per fossil fuel, proportional to the amount of carbon emissions released when burned,

- $\mathrm{CO}_{2}$ tax determined for each ton of $\mathrm{CO}_{2}$ emission released into the air,

- The energy tax released per specific energy unit.

These taxes, which are still low, are expected to have a high-income volume. A study by the United Nations (UN) reveals that a $\$ 21$ global tax per ton of carbon can generate $\$ 125$ billion in revenue annually (UN General Assembly, 2001). On the other hand, these taxes are expected to encourage organizations to take measures towards reducing carbon emissions, as they will cause financial losses for organizations.

In addition to positive thoughts and expectations, there is also the idea that keeping taxes low will not have a reducing effect on emissions. Although carbon taxes are currently applied at national level in some European countries such as Sweden, Norway, the Netherlands, Denmark, Finland and Italy, they are still a proposal on a global scale. Sustainable emission reduction is possible by a globalized tax system and revenues for emission reduction technologies, alternative fuel and energy sources with less carbon emissions.

\section{Carbon trading}

One of the carbon footprint management mechanism that have emerged with the Kyoto Protocol is carbon trade. Carbon trade is defined as' purchasing contracts that arise when a buyer pays another party in exchange for the loans that he / she will use to fulfill his commitments for carbon reduction and express the right to deduct a certain amount of carbon emissions' (Tunahan, 2010). Carbon trade provides cooperation between developed countries and undeveloped countries, and compensates for the emissions that are higher than the commitment of the developed country's carbon surplus. Carbon or in other words, emissions trading, have created a growing market for itself. Participants of this market are giving the money of excess carbon they release to the atmosphere to sustainable development initiatives in other undeveloped countries. Carbon markets consist of compulsory and voluntary markets. Mandatory markets enable the countries that have signed the Kyoto Protocol to trade carbon among themselves. Carbon, priced according to the supply-demand balance, is traded in the UK and USA Stock Exchanges, and forms its own index (Elitaş and Çetin, 2011; Duman et al., 2012).

Voluntary carbon markets are valid in sectors and in countries not covered by the Kyoto Protocol, and have a more complex structure than the mandatory carbon market. These markets, institutions and organizations, individuals, non-governmental organizations, etc. create and aim to reduce GHG emissions and are based on the principle of volunteering (Duman et al., 2012).

In order for a company or organization to make its GHG inventory available, this inventory must be validated and documented by an independent controller. Organizations usually create and verify GHG emission inventories, predicting that widespread sanctions on carbon costs will increase. In line with this study, taking measures to reduce economic losses through practices to identify energy efficiency opportunities and providing savings in both the short and long term is recommended. In addition, by publishing verified GHG inventory studies within the framework of transparency, it increases the reputation and brand value of the institution.

\section{Determining and Calculating Carbon Footprint in the Construction Sector}

The population growth in Turkey is mainly based on improved social and economic opportunities in especially urban areas. This situation has increased the need for infrastructure and superstructure; thus, directly affected the construction industry.

The share of the construction sector was $15 \%$ in the global economy at the beginning of 2017 , and this ratio in Turkey has been identified as $9 \%$ (Url-6; Haidery and Baş, 2020). The construction sector has become the most popular sector in recent years as a result of the growth momentum of the country's economy, and the need for housing and infrastructure brought by the concentration of the population in large cities approved by the government policies and reflected in the investment plans. The Gross National Product (GNP) of Turkey in 2013 until 2017 is shown in Figure 5 together with the growth of the construction sector (Url-6). By 2025, it is estimated that the share of the construction sector in the total economy will reach up to $10 \%$ in developed countries and $17 \%$ in developing countries (Url-6). Along with the growing economic share of the construction industry, all the processes from the production of the necessary materials till the completion of the construction and the operational process should be taken into consideration. Excess energy and fuel consumption, and generation of excess wastes are the main reasons for the construction sector to be highlighted in the overall carbon footprint contribution within the scope of this study. The importance of the sector in Turkey and at the world scale, GHG emissions in general and in the basic materials used, and specific benchmarks are covered in this section accordingly. 


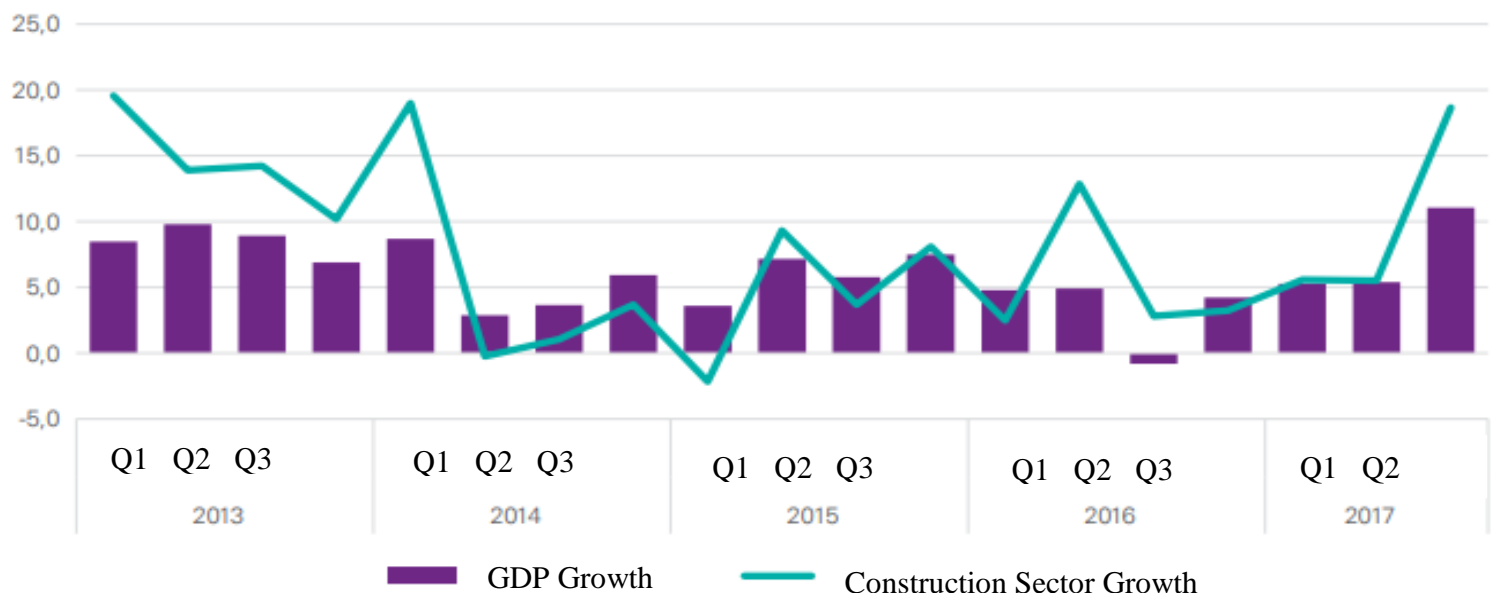

Fig. 5. Construction sector growth in Turkey with GNP (Url-6)

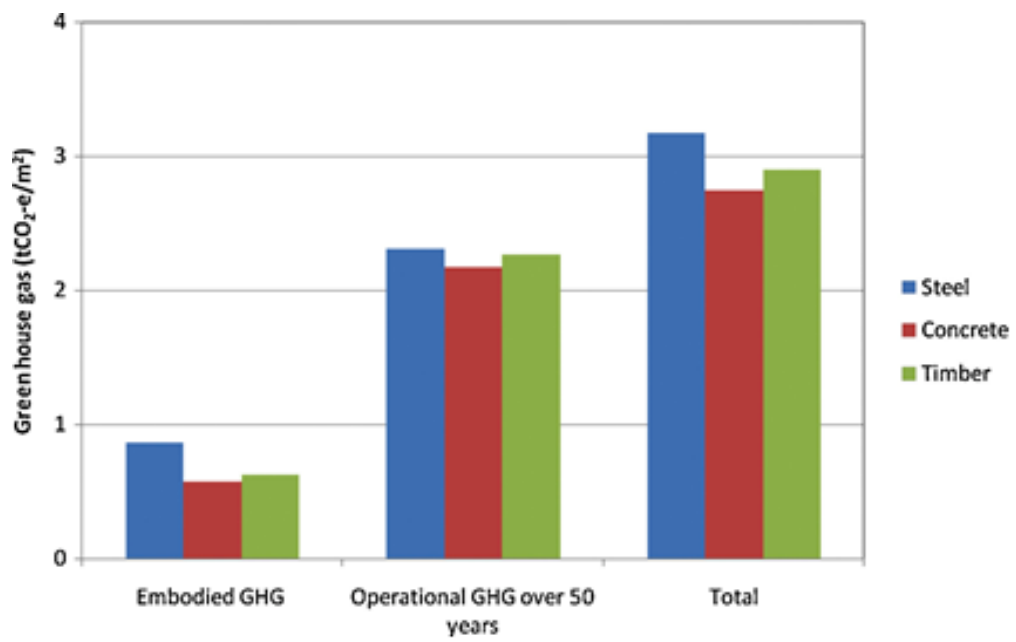

Fig. 6. GHG emissions of the three featured construction materials of eight-storey multi residential building (Aye et al., 2012).

\section{Construction Sector and GHG Emissions}

It is observed that there is an increasing deviation in targeted carbon emission reduction levels $(50 \%$ in 2025 compared to 1990 and $80 \%$ reduction in 2050) in line with the Paris Agreement, where limiting global warming to $1.5-2^{\circ} \mathrm{C}$ is dictated (Green Construction Board (GCB), 2015). On the road map published by the Green Construction Board (GCB), the reduction of GHG emissions in 2009 was $17 \%$ compared to 1990 , while it was only $11 \%$ in 2012 (Green Construction Board, 2015). In addition to its economic share, the construction sector has a significant impact on total GHG emissions with energy consumption and resource use from the supply chain. The synthesis report prepared for IPCC revealed that the construction sector was responsible for $18 \%$ of the direct and indirect GHG emissions worldwide in 2010 (IPCC, 2014). Comparison of GHG emissions pertaining to the construction and operation processes by three different building construction materials (steel, reinforced concrete and wood/timber) per unit area is referred in a case study of an eight storey multi residential building conducted by Aye et al (2012) as shown in Figure 6. These materials are responsible for significant environmental impacts through resource consumption, waste generation and GHG emissions during the construction and post-construction (operation) stages of buildings. Most policies and regulations focus on reducing direct emissions from buildings. Researches in recent years draw attention to indirect or life cycle GHG emissions of the construction industry. A new research on life cycle energy in buildings revealed that the energy consumed during construction may vary between $5 \%$ to $100 \%$ of the entire life cycle energy consumption (equal to $10 \%-97 \%$ of all life cycle carbon emissions) depending on the building's service life, energy requirements, location, and material usage (Chastas et al., 2016).

The most important factor in the indirect GHG emissions of the construction industry is the energy spent for the production of materials. The energy intensity in the material production is shown in Table 4. The great contribution of the energy spent during the construction to the GHG emissions indicates that it is possible to achieve global warming targets with the measures taken in the construction sector.

Turkey's construction sector has been the driving force of the economy in the recent years and has become an important parameter (EMIS, 2014). The growth rate of this sector, on the average, was higher than that of the general economy, but grew by an average of $4.3 \%$ 
between 2008 and 2013. Share of the construction sector in the world's economic growth as well as in Turkey directly affects the energy consumption. Turkey's total final energy consumption was 49.7 million tons of petroleum equivalents (TPE), respectively. The share of the construction sector in final energy consumption was 4.7\% (Ahmetoğlu, 2019). Total electricity consumption of the construction sector announced by TSI and subbreakdown of this consumption is tabulated in Table 5 .

Table 4. The energy intensity (GJ / unit) in the production of building materials adapted from (Treloar and Crawford, 2010).

\begin{tabular}{ccc}
\hline Material & Unit & Embodied energy coefficient (GJ/unit) \\
\hline Concrete (30 MPa) & $\mathrm{m}^{3}$ & 5.48 \\
Concrete (50 MPa) & $\mathrm{m}^{3}$ & 8.55 \\
Steel & ton & 85.46 \\
Formwork & $\mathrm{m}^{3}$ & 10.92 \\
Glass (4 mm) & $\mathrm{m}^{2}$ & 1.72 \\
Aluminum & ton & 252.60 \\
Cellulose Based Insulation (R:2.5; $100 \mathrm{~mm})$ & $\mathrm{m}^{2}$ & 2.17 \\
Wood & $\mathrm{m}^{3}$ & 10.92 \\
MDF (Medium Density Fiberboard) & $\mathrm{m}^{3}$ & 30.35 \\
Mortar & ton & 2.00 \\
\hline
\end{tabular}

Table 5. Total electricity consumption and percent breakdown of the consumption in construction sector of Turkey (Url-7).

\begin{tabular}{lcccccc}
\hline Sector & $\begin{array}{c}\text { Total Electricity } \\
\text { Consumption } \\
(\mathbf{M W h})\end{array}$ & $\begin{array}{c}\text { Product } \\
\text { and Service } \\
\text { Production } \\
(\boldsymbol{\%})\end{array}$ & Heating (\%) & $\begin{array}{c}\text { Air Conditioning } \\
(\%)\end{array}$ & $\begin{array}{c}\text { Lighting and } \\
\text { Electrical Office } \\
\text { Equipment (\%) }\end{array}$ & $\begin{array}{c}\text { Transportation } \\
(\%)\end{array}$ \\
\hline Construction & $3,064,628$ & 43.6 & 22.5 & 3.2 & 30.7 & 0,0 \\
\hline
\end{tabular}

In the operational breakdown of the electricity consumption of the construction sector published by TSI, the percent distribution of transportation was not shared. The reason for this may be the absence of electricity spent for transportation or the data related to this item may not be recorded.

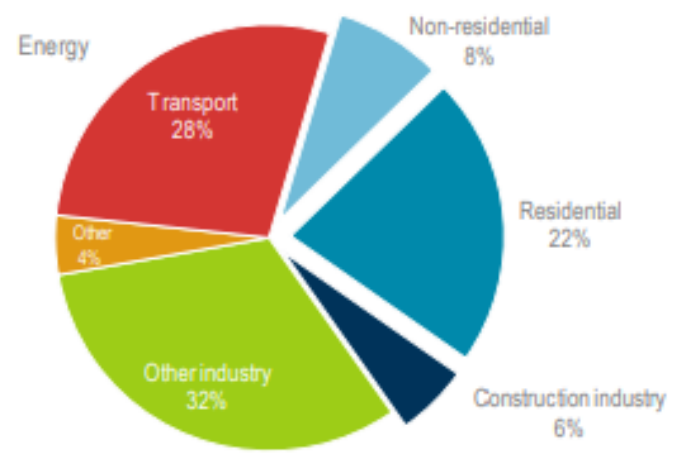

Fig. 7. Global energy consumption by sectors in 2015 (Abergel et al., 2017).

The use of electricity in buildings worldwide has increased by an annual average of $2.5 \%$, and electricity has accounted for about $70 \%$ of the total energy demand in buildings since 2010. In 2016, it was revealed by the International Energy Agency (IEA- International Energy Agency) that electricity represented $1 / 3$ of the total energy use in buildings (Abergel et al., 2017). Global energy consumption by sectors in 2015 is given in Figure 7 . The construction industry covers the general industry sector, including the production of materials for construction. Thus, it is seen that direct and indirect energy consumption has $6 \%$ share in energy consumption for the entire construction sector (Abergel et al., 2017).

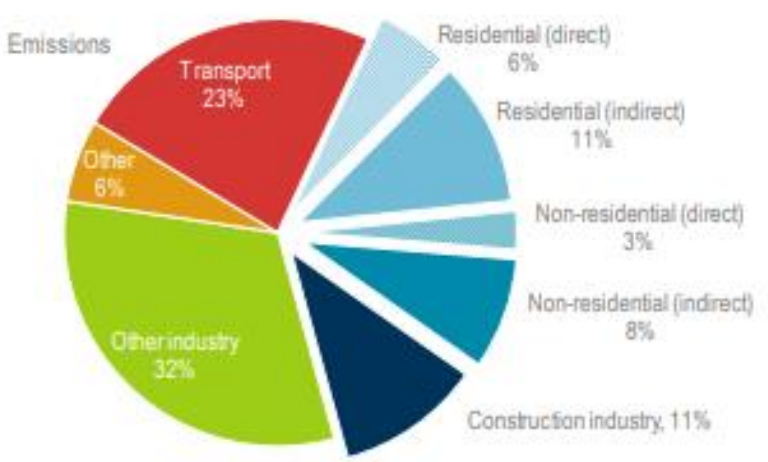

Fig. 8. Energy-related global $\mathrm{CO}_{2}$ emissions by sectors in 2015 (Abergel et al., 2017).

Buildings accounted for $28 \%$ of global energy-induced $\mathrm{CO}_{2}$ emissions in 2015 and for approximately $1 / 3$ of direct emissions from fossil fuel combustion. Depending on the location of the building, emissions in residential areas such as the city were comparatively higher in rural areas (Abergel et al., 2017). The construction of the buildings constituted $11 \%$ of the $\mathrm{CO}_{2}$ emissions from energy consumption (Figure 8). The total of GHG emissions resulting from the energy consumed during the construction and operation of the buildings, which were directly affected by the increase in the demand for superstructure with the increase in the population, constituted $39 \%$ of the emissions originating from energy.

Fossil fuels and energy consumed in all stages from material production to construction completion and in 
the operation of the buildings are regarded as the main causes of $\mathrm{CO}_{2}$ emissions. Moreover, there are different factors affecting carbon emissions such as building size, location, materials used, fossil fuel and energy consumption and waste generated during the construction phase. Cho and Chae (2016) found that materials used in construction activities in South Korea and their transportation constitutes $92.7 \%$ of total GHG emissions. Similar findings are frequently encountered worldwide.

\section{Emissions from the resources used in the sector}

The major resources used are cement and concrete, iron and steel, aluminum, wood and glass.

\section{Cement and concrete}

One of the basic elements of reinforced concrete structures, which is the most preferred building type recently, is cement, and its production requires high energy. Cement obtained by heating its mixture with limestone, clay and gypsum with water up to 1400 $1500^{\circ} \mathrm{C}$ has a great effect on $\mathrm{CO}_{2}$ emission. Approximately $5 \%$ of human-induced $\mathrm{CO}_{2}$ emissions emitted worldwide are due to cement production (Candemir et al., 2012).
Researches focus on the possibility of substituting cement in the concrete mix with mostly recyclable materials such as porcelain residues, recycled rubber and rubber, basalt aggregates, glass, ceramic aggregates (de Castro and de Brito, 2013; Usón et al., 2013; Medina et al., 2013; Ingrao et al., 2014; Kajaste and Hurme, 2016). Research on cement examines using alternative binders to reduce $\mathrm{CO}_{2}$ emissions. Concrete or ordinary Portland cement using binders such as activated alkali instead of ground granules shows that it reduces $\mathrm{CO}_{2}$ emissions between 55\% and 75\% (Yang et al., 2013; Kajaste and Hurme, 2016). $\mathrm{CO}_{2}$ emissions, which are the sum of the transportation and production of the components that make up concrete, the most important material of the construction industry, are given in Table 6. Some of the data appearing in the table includes GHG calculations for Eurasia Tunnel (Akan et al., 2017).

Turkey as the Europe's largest cement producer, follows China, India and the United States and is ranked at the fourth place (EMIS 2014; Kajas and Hurme, 2016). $\mathrm{CO}_{2}$ emissions from cement production in Turkey in 2011 reached 45.31 million tons and was again ranked as $4^{\text {th }}$ largest country after China, India and the United States (Kajas and Hurme, 2016).

Table 6. $\mathrm{CO}_{2}$ emissions of the components used in concrete production $\left(\mathrm{kg} \mathrm{CO}_{2} \mathrm{e} / \mathrm{m}^{3}\right.$ concrete) adapted from (Akan et al., 2017).

\begin{tabular}{ccc} 
Product & Description & $\begin{array}{c}\text { Total CO } \mathbf{C O}_{2} \mathbf{e} \\
\left(\mathbf{k g ~ C O}_{\mathbf{2}} \mathbf{e} / \mathbf{m}^{3} \text { concrete) }\right.\end{array}$ \\
\hline & CEM I 42,5 R-SR5 & 396.83 \\
Cement & CEM I 42,5 N & 399.35 \\
& CEM III/A 32,5 R & 211.14 \\
& CEM III/B (S) 32,5 N-SR & 122.08
\end{tabular}

\begin{tabular}{ccc} 
Fine Aggregate & Crushed Stone $(0-4 \mathrm{~mm})$ & 2.59 \\
Coarse Aggregate & Crushed Stone $(5-10 \mathrm{~mm})$ & 2.69 \\
Sand & Crushed Stone $(10-20 \mathrm{~mm})$ & 2.63 \\
\hline Fly Ash & Natural Sand $(0-3 \mathrm{~mm})$ & 3.31 \\
\hline Admixtures & Type F & 1.25 \\
\hline
\end{tabular}

\section{Iron and Steel}

Since iron and steel industry is a sector with high-energy consumption, it causes high GHG emissions. Within the scope of different national and international environmental programs, it is aimed to reduce these emissions and energy consumption intensities. Turkey's metal industry accounts for approximately $27.6 \%$ of the total energy consumption (Url-8). Crude steel production in 2013 dropped to 34.6 million tons; despite this decline of $3.4 \%$, Turkey maintained its position as the $8^{\text {th }}$ world's largest steel producer (EMIS, 2014). Considering the intensive production and energy consumption, it may be possible to reduce $\mathrm{GHG}$ emissions by passing to production methods such as scrap electric arc furnace and steel production based on recycling. In the research carried out on different production methods, it was determined that approximately 9-12.5 GJ energy was consumed during the production of 1 ton steel in scrap and electric arc furnaces, and this value was 28-31 GJ with the blast furnace and basic oxygen furnace production method. It was concluded that $1888-1968 \mathrm{~kg}$ $\mathrm{CO}_{2}$ is generated in the production of 1-ton raw steel with blast furnace and this value is $455-667 \mathrm{~kg} \mathrm{CO}_{2}$ for a plant with electric arc furnace (Schuler et al., 2013; Biyık and Özkale, 2017). In addition, it is stated that $\mathrm{CO}_{2}$ emissions per ton steel can be reduced by $26.2 \%$ $(1.54-2.12 \mathrm{t})$ and $56.5 \%(1.17-1.75 \mathrm{t})$, respectively with new technological applications such as $\mathrm{CO}_{2}$ capture and storage in ore blast furnace production method (Jin et al., 2017).

\section{Aluminum}

Aluminum, the most produced metal after steel in the world, is used extensively in the construction sector especially in roof and facade coatings, door and window productions, stairs, scaffolding and greenhouse constructions. It has a wide usage area with its features 
such as lightness, long life, easy form, resistance against external factors and different climatic conditions, low maintenance cost, and colorization on a wide scale. While primary aluminum production was 5304 thousand tons worldwide as of January 2019, its distribution by regions is shown in Figure 9.

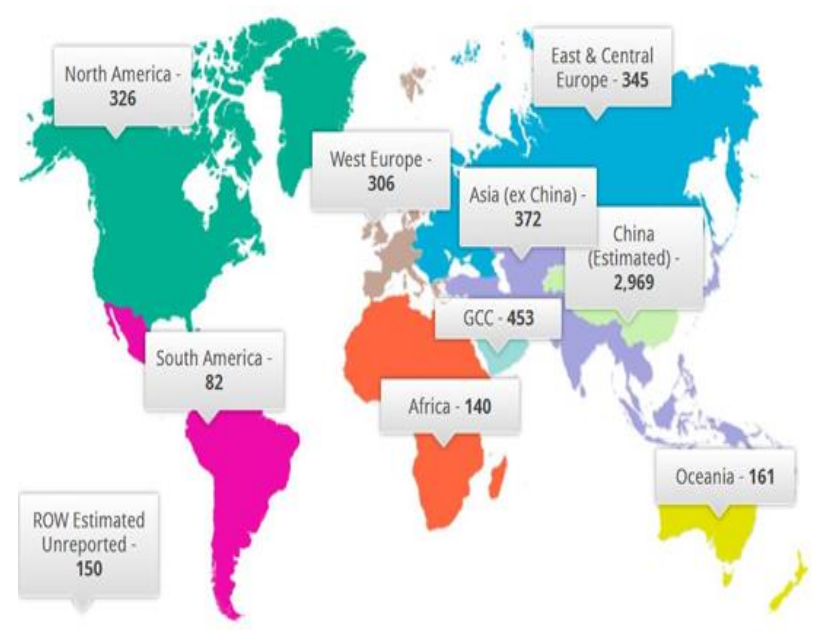

Fig. 9. Distribution of aluminum production (thousand tons) by region in 2019 (Url-9).
China ranks first in the world in aluminum production with a share of about $56 \%$. Considering the sector-based distribution of aluminum on a global scale, the construction sector ranks first in 2017 with the transportation sector with a share of $26 \%$ (Url-10). The distribution of the aluminum requirement on a sectoral basis is shown in Figure 10.

While $21 \%$ of global GHG emissions originate from industrial activities, the share of the aluminum industry in these emissions is $1 \%$ (Gautam et al., 2018). Requiring high-energy consumption for melting and other processes in aluminum production makes it imperative to take measures to achieve the global warming targets set in the Kyoto Protocol and the Paris Agreement. For example, the energy used for aluminum production in the USA has decreased by $64 \%$ in the last 45 years. While the share of energy efficiency provided by new technology applications in this decrease is $22 \%$, the share of increase in recycling is $42 \%$ (Das and Green, 2010). In the UK, with the measures taken, while the total $\mathrm{CO}_{2}$ emission was 4352 thousand tons in 1990 , this value was reduced to approximately 446 thousand tons in 2016 (Url-11).

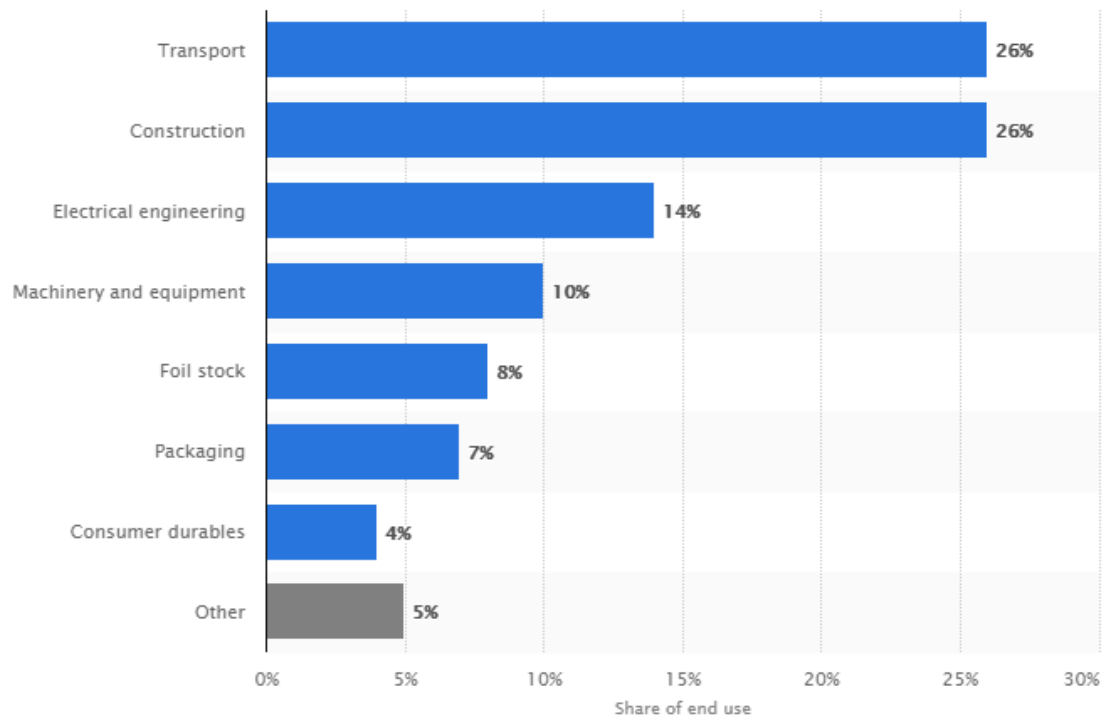

Fig. 10. Distribution graph of aluminum on a sectoral basis (Url-10).

\section{Wood}

Wood is one of the building materials used since ancient times. Its properties like lightness, resistance against different climatic conditions, increased fire resistance with special paints, protection against rotting and insect damage by processes, rebuilding ability when the structure is dismantled, repeated usability energyfriendly and earthquake resistant made wood material widespread in the construction industry. It can also be used in perfect harmony with steel, concrete, stone and adobe.

Gustavsson et al. (2006) compared net $\mathrm{CO}_{2}$ emissions from the construction of concrete and wooden buildings. They revealed that recycling wood residues, including timber, construction and demolition waste, reduces wood $\mathrm{CO}_{2}$ emissions.

\section{Glass}

Glass is a building material that is preferred for visual design and used for different purposes with different color, texture and shape alternatives in the construction industry. In addition, glass is defined as an auditory, visual comfort, aesthetic, natural, recyclable and environmentally- friendly building material.

Glass, unlike plastic and paper, can be recycled unlimited. With the recovery of glasses the life of the storage areas is extended, conservation of natural resources is ensured, and waste disposal costs are reduced. The most important advantage of recycling 
glasses is the reduction of the high-energy need used in glass production, especially in the melting phase. $25 \%$ less energy is used in re-glass production from waste glasses. In addition, GHG emissions released during glass production are reduced by $20 \%$ during re-glass production from waste glasses (Savc1 and Dikmen, 2015).

\section{Construction machinery and equipment use}

The use of construction machinery and other equipment is one of the main factors that cause environmental problems such as GHG emissions and noise during the construction phase. Most of the work machines used in Turkey are old instruments that are insufficiently maintained. It is possible to contribute to the reduction of GHG emissions by replacing vehicles with new vehicles using diesel fuel. In addition, according to the EPA announcement in 2009 , a $10 \%$ drop in diesel fuel use will reduce $\mathrm{CO}_{2}$ emissions arising from construction sector by about 5\% (EPA, 2009; Yi et al., 2017)

\section{Conclusions and Recommendations}

Global warming caused by GHG emissions increase worldwide resulting from unconscious consumption and anthropogenic activities. As such, the reduction of these emissions is a principle adopted all over the world and is targeted by countries. The rapid increase in the construction industry on a global scale has caused a significant share of GHG emissions and carbon footprint. Therefore, in this study, detailed information is provided on these trendy topics to increase public awareness. Various measures are being implemented to reduce the carbon footprint in the world. The suggestions for minimizing the consumption of fossil fuels, particularly electricity consumption, and waste generation have gained interest. Carbon footprint studies in Turkey should not be regarded as necessitated by the international platforms involved or as obligation of commitments. More calculations regarding production, construction, service, energy sectors should be provided and encouraged. A sustainable environmental awareness should be created by forming a national database. Regular monitoring of the processes for verifying the calculations is also required. National memory should be created with carbon footprint studies and sampling without sectoral discrimination. Depending on the calculations made and the findings obtained, mitigation measures must be implemented. By considering the amortization period and costs of the mitigation measures by the experts; it is important to realize efficient calculations and providing incentives for special applications.

\section{Conflict of interest statement}

We declare that we have no conflict of interest.

\section{References}

Abergel, T., Dean, B., Dulac, J. (2017). Towards a zeroemission, efficient, and resilient buildings and construction sector: Global Status Report 2017. UN
Environment and International Energy Agency. Paris, France.

Ahmetoğlu, S. (2019). Carbon footprint in construction sector and sample calculations (MSc thesis). İstanbul Technical University, İstanbul, Turkey. (In Turkish)

Akan, MOA., Dhavale, DG., Sarkis, J. (2017). Greenhouse gas emissions in the construction industry: An analysis and evaluation of a concrete supply chain. Journal of Cleaner Production, 167, 1195-1207.

Alıc1, B., Y1ldız, H. (2012). Carbon tax ant its efficient use in the protection of the environment that is a global public good. Journal of Law and Economics Research, 4(1), 55-61. (In Turkish)

Aye, L., Ngo, T., Crawford, R. H., Gammampila, R., Mendis, P. (2012). Life cycle greenhouse gas emissions and energy analysis of prefabricated reusable building modules. Energy and Buildings, 47, 159-168.

Bayırhan, İ., Mersin, K., Tokuşlu, A., Gazioğlu, C. (2019). Modelling of Ship Originated Exhaust Gas Emissions in the Strait of Istanbul (Bosphorus). International Journal of Environment and Geoinformatics, 6(3), 238-243. DOI: 10.30897/ijegeo.641397.

Biyik, Y., Özkale, L. (2017). Relationship between the iron and steel industry production methods and export, added value and carbon emission reduction policies. International Journal of Management Economics and Business, 13(5), 718-735. (In Turkish)

Candemir, B., Beyhan, B., Karaata, S. (2012). Sustainability in Construction: Green Building and Nanotechnology Strategies. TUSIAD Publications No: TUSIAD-T-2012-10-/533. İstanbul: Sis Printing Press, 134 p. (In Turkish)

Chastas, P., Theodosiou, T., Bikas, D. (2016). Embodied energy in residential buildings-towards the nearly zero energy building: A literature re-view. Building and Environment, 105, 267-282.

Cho, S. H., Chae, C. U. (2016). A study on life cycle $\mathrm{CO} 2$ emissions of low-carbon building in South Korea. Sustainability, 8(6), 579.

Das, S. K., Green, J. A. (2010). Aluminum industry and climate change-assessment and responses. The Journal of the Minerals, Metals and Materials Society JOM, 62(2), 27-31.

De Castro, S., De Brito, J. (2013). Evaluation of the durability of concrete made with crushed glass aggregates. Journal of Cleaner Production, 41, 7-14.

Duman, H., Özpeynirci, R., Yücenurşen, M., Bağc1, H. (2012). Carbon accounting. Journal of Social Economic Research, 12 (24), 105-120. (In Turkish).

Edenhofer, O., Pichs-Madruga, R., Sokona, Y., Minx, J. C. (2014). Change 2014: Mitigation of Climate Change. Contribution of Working Group III to the Fifth Assessment Report of the Intergovernmental Panel on Climate Change. Cambridge University Press, $16 \mathrm{p}$.

Elitaş, C., Çetin, CA. (2011). Carbon Trade and Carbon Banking. Accounting and Auditing Overview, 51-78. (In Turkish) 
EMIS. (2014). Construction Sector in Turkey. https://www.emis.com/sites/default/files/EMIS\%20In sight $\% 20$ -

\%20Turkey\%20Construction\%20Sector\%20Report.p df. Last accessed on 12.04.2020

EPA. (2009). Potential for reducing greenhouse gas emissions in the construction sector. Sector strategies, EPA, Washington, DC, USA, $45 \mathrm{p}$.

Firat, S. Ü., Yurtsever, Ö., İleri, C.., Kıvılcım, İ. (2017). Towards a Sustainable World: Global Agenda and Turkey. Economic Development Foundation, Publication No: 294, İstanbul, 111 p. (In Turkish)

Gautam, M., Pandey, B., Agrawal, M. (2018). Carbon footprint of aluminum production: emissions and mitigation. In Chapter 8 Environmental Carbon Footprints- Industrial Case Studies, 197-228, Butterworth-Heinemann, $474 \mathrm{p}$.

Gazioğlu, C. (2018). Biodiversity, Coastal Protection, Promotion and Applicability Investigation of the Ocean Health Index for Turkish Seas. International Journal of Environment and Geoinformatics, 5(3), 353-367. DOI: 10.30897/ijegeo.484067.

Green Construction Board, (2015). Low Carbon Route map for the Built Environment: 2015 Route map Progress- Technical Report.

Gustavsson, L., Pingoud, K., Sathre, R. (2006). Carbondioxide balance of wood substitution: comparing concrete-and wood-framed buildings. Mitigation and Adaptation Strategies for Global Change, 11(3), 667-691.

Haidery, J., Baş, B. (2020). Life Cycle Assessment of Construction of Water Supply Pipelines: A Case Study from Van, Turkey. International Journal of Environment and Geoinformatics, 7(1), 23-32. DOI: 10.30897/ijegeo.687547.

Ingrao, C., Giudice, A. L., Tricase, C., Mbohwa, C., Rana, R. (2014). The use of basalt aggregates in the production of concrete for the prefabrication industry: Environmental impact assessment, interpretation and improvement. Journal of Cleaner Production, 75, 195-204.

IPCC (2014). Climate Change 2014: Synthesis Report. Contribution of Working Groups I, II and III to the Fifth Assessment Report of the Intergovernmental Panel on Climate Change [Core Writing Team, R.K. Pachauri and L.A. Meyer (eds.)]. IPCC, Geneva, Switzerland, $151 \mathrm{p}$.

Jin, P., Jiang, Z., Bao, C., Hao, S., Zhang, X. (2017). The energy consumption and carbon emission of the integrated steel mill with oxygen blast furnace. Resources. Conservation and Recycling, 117, 58-65.

Kajaste, R., Hurme, M. (2016). Cement industry greenhouse gas emissions-management options and abatement cost. Journal of Cleaner Production, 112, 4041-4052.

Kulu, MB. (2001). Environmental Taxes and Applications in Developed Countries. Tax World, 234, 50. (In Turkish)

Medina, C., de Rojas, M.I.S., Frías, M., (2013). Freezethaw durability of recycled concrete containing ceramic aggregate. Journal of Cleaner Production, 40, 151-160.
Özsoy, CE. (2015). Low carbon economy and Turkey's carbon footprint. Hak İs International Journal of Labor and Society, 4(9). (In Turkish)

Savc1, S., Dikmen, CB. (2015). Reassessment of Glass Materials as Resources of Recycling in Construction Sector, ISBS, 2nd International Sustainable Buildings Symposium, Proceedings Ankara, 28-30 May 2015, 694-697.

Schuler, F., Voigt, N., Schmidt, T., Woertler, M., Dahlmann, P., Ghenda, J. T., Luengen, H. B. (2013). Steel's Contribution to a Low-Carbon Europe 2050. Stahl und Eisen, 133(9), 61-63.

Sunturlu, Ö. (2017). Determination of the carbon footprint of boats operating in tourism sector: Case study of Muğla (MSc thesis).Muğla Sttk1 Koçman University, Muğla, Turkey. (In Turkish)

Talapatra, A. (2019). Thermodynamic and Kinetic Desorption Analysis on Direct Air Capture of $\mathrm{CO} 2$ Gas Using Moisture Swing Sorbent. International Journal of Environment and Geoinformatics, 6(2), 186-191. DOI: 10.30897/ijegeo.526921

Toröz, A.S. (2015). Determination of the carbon footprint in a waste acceptance facility receiving ship-wastes (PhD thesis). Istanbul Technical University (ITU), Istanbul, Turkey. (In Turkish)

Treloar, G.J., Crawford, R.H. (2010). Database of embodied energy and water values for materials. Melbourne: The University of Melbourne, Melbourne.

Tunahan, H. (2010). Carbon financing as a way to reduce global climate change. Accounting and Finance Journal, 46,199-215(In Turkish)

Ülker, D., Ergüven, O., Gazioğlu, C. (2018). Socioeconomic impacts in a Changing Climate: Case Study Syria. International Journal of Environment and Geoinformatics, 5(1), 84-93. DOI: 10.30897/ijegeo.406273

UN General Assembly. (2011). Preparatory Committees for the International Conference on Financing for Development, Technical Note No: 3 Existing Proposals for Innovative Source of Finance 20, New York, United Nations.

Url-1:http://www.globalcarbonatlas.org/en/CO2emissions, 12.04.2020.

Url-2:http://www.tuik.gov.tr/PreIstatistikTablo.do;j sessionid=TPJ2W0hYyr6wDcHdg6NySGWyQJKz11 qrkxYTx2Jvn7g1gcWXc0WH!898620440?istab_id= 9022, 12.04.2020.

Url-3. http://www.tuik.gov.tr/PreTablo.do?alt_id=1019, 10.04.2020

Url-4: http://www.tuik.gov.tr/PreHaberBultenleri.do?id=33 $624,12.04 .2020$

Url-5:http://www.karem.org.tr/images/galeri/4.pdf, 12.04.2020

Url-6: https://assets.kpmg/content/dam/kpmg/tr/pdf/2018/01 /sektorel-bakis-2018-insaat.pdf, 12.04.2020.

Url-7: http://www.tuik.gov.tr/PreHaberBultenleri.do?id=27 $667,12.04 .2020$ 
Url-8: $\quad$ https://www.eigm.gov.tr/tr-TR/Denge-

Tablolari/Denge-TablolariDenge-Tablolari,

01.04.2020.

Url-9:http://www.world-aluminium.org/statistics/\#map, 01.04.2020.

Url-10: https://www.statista.com/statistics/280983/shareof-aluminum-consumption-by-sector/, 12.04.2020.

Url-11:

https://www.statista.com/statistics/485475/greenhous -gas-emissions-from-the-aluminum-production-uk/ 01.04.2020.

Usón, AA., López-Sabirón, AM., Ferreira, G., Sastresa, EL. (2013). Uses of alternative fuels and raw materials in the cement industry as sustainable waste management options. Renewable and Sustainable Energy Reviews, 23, 242-260.

Vural, IY. (2012). Carbon tax in combating climate change (In Turkish).

Wintergreen, J., Delaney, T. (2007). ISO 14064, International Standard for GHG Emissions Inventories and Verification. In Boonton, NJ: First Environment, Inc.

WRI/WBCSD (2004). World Resources Institute/world Business Council for Sustainable Development, Greenhouse Gas Protocol.

WWF- Turkey. (2012). Turkey's Ecological Footprint Report. 89 p. (In Turkish)

Yang, K.H., Song, J.K., Song, K., (2013). Assessment of $\mathrm{CO}_{2}$ reduction of alkali-activated concrete. Journal of Cleaner Production, 39, 265-272.

Yi, CY., Gwak, HS., Lee, DE. (2017). Stochastic carbon emission estimation method for construction operation. Journal of Civil Engineering and Management, 23(1), 137-149. 